\title{
AN EVALUATION OF GAS DENSITY DEPENDENCE OF ANAESTHETIC VAPORIZERS
}

\author{
L. Prins, J. Strupat, J. Clement and R.L. Knill
}

\begin{abstract}
Agstract
Four commonly used vaporizers were studied for the effect of carrier gas density on vaporizer output. Vapour concentrations from a halothane Cyprane (Fluotec) Mark 2 increased in relation to the density of carrie $r$ gas, whereas the concentrations delivered by an enflurane Ohio vaporizer decreased. The halothane Cyprane (Fluotec) Mark 3 and enflurane Cyprane vaporizers were largely independent of density. Of clinical importance, nitrous oxide/oxygen (75/25), compared with oxygen alone, increased the vapour concentration outputs of the halothane Mark 2 up to 30 per cent and decreased the outputs of the enflurane Ohio unit up to 20 per cent.
\end{abstract}

PREvious observations suggest that the anaesthetic outputs of commonly used vaporizers vary with the composition of carrier gas ${ }^{1.2}$. Nitrous oxide, 60 to 70 per cent with oxygen, was reported to increase the yapour concentration outputs of a halothane vaporizer (Cyprane MK.2)' and two enflurane vaporizers (Ohio and Cyprane) ${ }^{2}$. These effects were attributed to redistribution of flow resistances within these vaporizers by increased carrier gas density.

To explore further the hypothesis that vaporizer function depends upon the density of cartier gas, we measured the output responses of four commonly used vaporizer's to carrier gases of widely varying density and viscosity.

\section{Methods}

The four vaporizers studied were two models of the Cyprane (Fluotec) halothane vaporizer, the Mark 2 and Mark 3, and the enflurane vaporizers manufactured by Ohio and Cyprane. All four units had been calibrated recently by the manufacturer. Each vaporizer was placed on a flat surface and fitted with a rigid metal extension incorporating a sampling port $35 \mathrm{~cm}$ distal to the vaporizer outlet.

L. Prins, R.R.T.; J. Strupat, R.R.T.; J. Clement, R.N.; and R.L. Knill, M.D.,F.R.C.P.(C). Departments of Anaesthesia and Respiratory Technology, University Hospital, University of Western Ontario, London. Ontario.

Address reprint requests to: Mr. L. Prins, Clinical Instructor, Department of Respiratory Technology, University Hospital, P.O. Box 5339, Postal Station A, London, Ontario, N6A 5A5.

This work was supported by a grant from Ohio Medical Products.
For this study, we selected carrier gases and carrier gas mixtures which have a wide range of gas density; these were helium with oxygen (50/50), nitrogen, oxygen, carbon dioxide with oxygen (10/90), nitrous oxide with oxygen $(80 / 20)$, nitrous oxide and $\mathrm{SF}_{6}$ with nitrous oxide (9.5/90.5). Each gas or gas mixture was delivered from calibrated rotameters set to give a total flow rate of $6 \mathrm{l} / \mathrm{min}$, this rate having been verified by a timed collection of gas with a Collins watersealed spirometer.

Carrier gases were introduced suddenly into the inlet of each vaporizer and kept constant while outlet vapour concentrations were measured at dial settings of $0.5,1.0,1.5,2.0,2.5$ and 3.0 per cent. Vapour concentrations were recorded two to three minutes after establishing each condition of carrier gas and dial setting; in preliminary studies we found that changes in vaporizer output were always complete within 120 seconds and remained stable for at least 30 minutes.

The concentrations of both yapours (halothane and enflurane) and all carrier gases except helium were measured by a Perkin-Elmer \#1100 mass spectrometer. Helium cannot be analyzed in our laboratory and its concentration was only inferred from rotameter settings. Vapour concentrations in the helium/oxygen mixture were determined by a Beckman infrared analyzer with a halothane pickup head purged with helium/oxygen (50/50). Both mass spectrometer and infrared analyzers were calibrated on each testing day with certified test gases and vapours (Canadian Liquid Air for carrier gases and Scott's Specialty Gases for halothane and enflurane). Gas densities and viscosities were found in standard tables of physical characteristics of gases. ${ }^{3}$ 


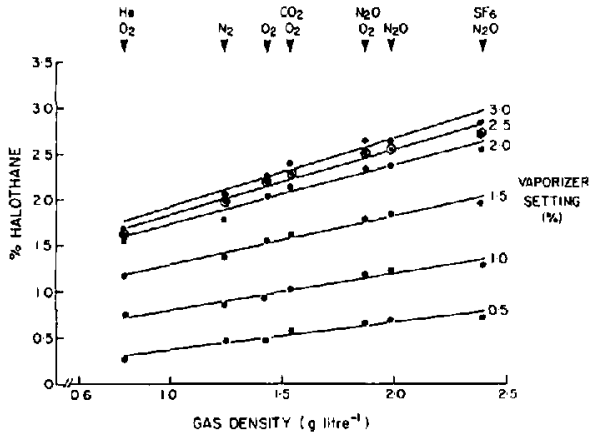

Figure I Effect of carrier gas composition and density on the function of a halothane Cyprane Mark 2 vaporizer. Points represent vapour concentration outputs observed for each combination of dial setting (indicated on the right), carrier gas (indicated at the top), and carrier gas density (at the bottom). At all settings, increasing density increased vaporizer output.

\section{RESULTS}

The vapour outputs of the halothane Сургаne Mark 2 and enflurane Ohio vaporizers varied with the composition of carrier gas. As this variation was clearly correlated to carrier gas density and not to viscosity, we present our results in the form of graphs relating vapour output to carrier gas density. Density varied from $0.80 \mathrm{~g} \cdot$ litre $^{-1}$ to $2.4 \mathrm{~g} \cdot$ litre $^{-1}$ (Figures 1-4).

Increasing carrier gas density increased the vapour concentration output of the halothane Cyprane Mark 2 (Figure 1) and reduced the output of the enflurane Ohio vaporizer (Figure 2). Vapour concentrations emerging from the halothane Cyprane Mark 3 and enflurane Cyprane vaporizers were generally constant and independent of carrier gas composition (Figure 3, Figure 4), although there may have been a slight density dependence of the Mark 3 unit at higher dial settings.

In Tables I and II, we predict the densityrelated effects of nitrous oxide/oxygen (75/25) and hyperbaric pressure on the function of the halothane Mark 2 and enflurane Ohio vaporizers. These predictions are based on the computed least squares linear regressions of vaporizer output as a function of gas density at each dial setting. (Computed regressions are shown as lines in the Figures.) It should be noted that the predicted changes in vapour output with hyperbaric pressure (Table II) do not refer to changes in vapour concentration (which is determined in part by barometric pressure per se because it is equiv.

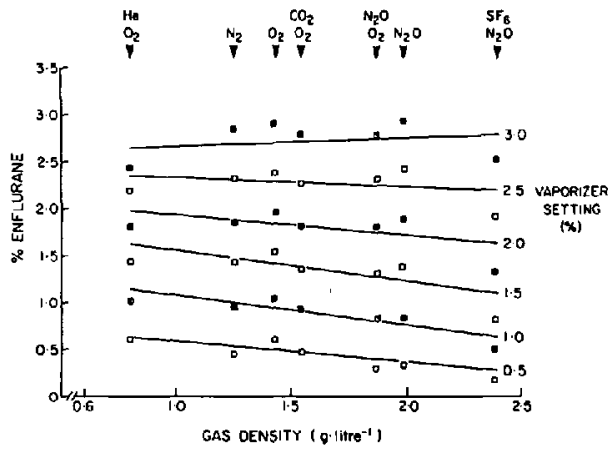

Figure 2 Outputs of the enflurane Ohio vaporizer for the same conditions as in Figure 1. Increasing carrier gas density generally reduced vaporizer output.

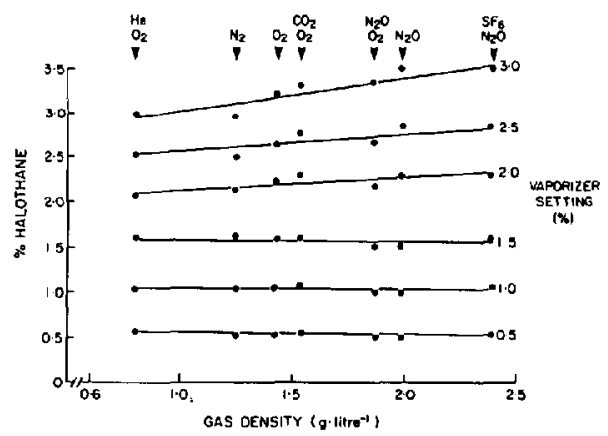

Figure 3 Outputs of the halothane Cyprane Mark 3 vaporizer were constant and independent of carrier gas at settings below 2.0 per cent. They became slightly density dependent at 2.0 and 2.5 per cent and more obviously density dependent at 3.0 per cent. with increasing density tending to augment output.

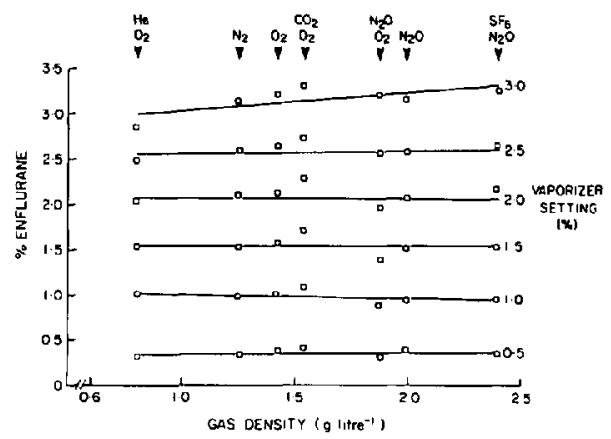

Figure 4 Outputs of the enflurane Cyprane vaporizer were constant and independent of carrier gas compositions at all dial settings tested. 
TABLE I

EfFect of Nitrous OxIDE AND OXYGEN (75/25) ON VAPORIZER OUTPUTS*

\begin{tabular}{ccccc}
\hline \hline \multicolumn{2}{c}{ Halothane Mk II } & & \multicolumn{2}{c}{ Enflurane Ohio } \\
\cline { 1 - 2 } $\begin{array}{c}\text { Vaporizer } \\
\text { setting } \\
\text { (per cent) }\end{array}$ & $\begin{array}{c}\text { Percentage } \\
\text { change in } \\
\text { output }\end{array}$ & & $\begin{array}{c}\text { Vaporizer } \\
\text { setting } \\
\text { (per cent) }\end{array}$ & $\begin{array}{c}\text { Percentage } \\
\text { change in } \\
\text { output }\end{array}$ \\
\hline 0.5 & +28 & & 0.5 & -20 \\
1.0 & +19 & & 1.0 & -15 \\
1.5 & +15 & & 1.5 & -10 \\
2.0 & +15 & & 2.0 & -6 \\
2.5 & +15 & & 2.5 & -2 \\
3.0 & +15 & & 3.0 & +2 \\
\hline
\end{tabular}

*Compared to output with oxygen (1.00).

TABLE II

Predicted Effect of Hyperbaric Pressure on VAPORIZER OUTPUTS

\begin{tabular}{ccccc}
\hline \multicolumn{2}{c}{ Halothane Mk II } & & \multicolumn{2}{c}{ Enflurane Ohio } \\
\cline { 1 - 2 } \cline { 5 - 5 } $\begin{array}{c}\text { Vaporizer } \\
\text { setting } \\
\text { (per cent) }\end{array}$ & $\begin{array}{c}\text { Percentage } \\
\text { change in } \\
\text { output/atm }\end{array}$ & & $\begin{array}{c}\text { Vaporizer } \\
\text { setting } \\
\text { (per cent) }\end{array}$ & $\begin{array}{c}\text { Percentage } \\
\text { change in } \\
\text { output/atm }\end{array}$ \\
\hline 0.5 & +64 & & 0.5 & -75 \\
1.0 & +66 & & 1.0 & -53 \\
1.5 & +47 & & 1.5 & -38 \\
2.0 & +46 & & 2.0 & -23 \\
2.5 & +45 & & 2.5 & -10 \\
3.0 & +48 & & 3.0 & +1 \\
\hline
\end{tabular}

alent to the ratio of vapour pressure to barometric pressure), but rather to changes in absolute vapour partial pressure.

\section{Discussion}

Stoelting observed that the halothane concentrations delivered by a Cyprane (Fluotec) Mark 2 vaporizer were markedly affected by either nitrous oxide or helium in the carrier gas.' $\mathrm{Com}-$ pared with oxygen, nitrous oxide increased the ouput of this vaporizer at dial settings of $0.1,0.5$ and 1.0 per cent, while helium in carrier gas reduced output. These phenomena were considered to be related to the density of the carrier gas (nitrous oxide more dense and helium less dense than oxygen), with density affecting the relative flow-resistances of by-pass and vaporizing chamber channels and thus the proportion of flow to the vaporizing chamber and vaporizer output. ' Paterson, et al. had previously observed that the outputs of the newer halothane Cyprane (Fluotec) Mark 3 model did not share this dependence upon carrier gas composition, at least with respect to nitrous oxide. ${ }^{4}$ Recently, Nawaf and Stoelting reported that the enflurane vaporizers manufactured by Ohio and Cyprane both increased their outputs when nitrous oxide was included in the carrier gas, presumably by a density mechanism akin to that proposed for the halothane Cyprane Mark 2. ${ }^{2}$ The purpose of the present study was to examine vaporizer re. sponses to a wider variation in carrier gas composition and properties, in order to magnify and better to quantitate any density or viscosity related effects.

In agreement with the previous studies of the halothane Cyprane vaporizers, ${ }^{1,4}$ we found that nitrous oxide compared with oxygen clearly increased the output of the Mark 2 model, while having little or no effect on the Mark 3 at dial settings below three per cent (Figure 1, Figure 2). The magnitudes of nitrous oxide effect we observed concur closely with the data presented in the previous reports. ${ }^{1.4}$ Our additional finding that the outputs of the Mark 2 model varied in direct relation to the gas densities of seven different gases or gas mixtures supports the hypothesis of a density-related mechanism. We suspect that increased carrier gas density in the Mark 2 increases vaporizer output by increasing the proportion of gas flow through the vaporizing chamber, as a result of augmented resistance to flow in the by-pass channel (regulated by the concentration control valve). This assumes that bypass flow resistance is more density dependent (i.e. turbulent) than vaporizer chamber resistance, a not unreasonable assumption considering the structure of this unit. ${ }^{5}$ The Mark 3 model probably behaves in a "density-independent" fashion because of a different arrangement of internal resistances. ${ }^{5}$ In this unit, there are restrictions to carrier gas flow (controlled by the concentration control valve) at the inlet of the by-pass channel and at both the inlet and outlet of the vaporizing channel, all of which are probably density-dependent. Thus, any changes in flow resistance due to density might well be distributed proportionately between by-pass and vaporizing channels, making the division of gas flow between the two, and thus vaporizer output, density independent.

The present study does not confirm the observations of Nawaf that nitrous oxide increases the output of both the enflurane Ohio and enflurane 
Cyprane vaporizers. With respect to the Ohio unit, we observed that nitrous oxide reduced output and that output generally varied inversely with gas density over the range of gas densities we tested (Figure 3 ). The enflurane Cyprane vaporizer was found to be carrier gas independent (Figure 4). The basis for the differences between these results and those of Nawaf is not clear. The construction of the Ohio unit is such that carrier gas flow is diverted into three channels; an open by-pass channel of fixed dimensions, a by-pass channel whose resistance is controlled by the concentration adjust valve and a vaporizer chamber inlet in which resistance is also controlled by the concentration adjust valve. ${ }^{6}$ We explain our results by hypothesizing that the flow resistance of the concentration adjust valve is dependent upon gas density. so that as density increases the proportion of flow through the fixed by-pass channel increases and, therefore, the vaporizer output decreases. One would expect this effect to be most pronounced at the lower settings, when the resistance to the vaporizer inlet channel is the greatest and this, indeed, is what we observed (Figure 3). The construction of the Cyprane enflurane vaporizer is nearly identical to that of the halothane Cyprane Mark 3 discussed above and the basis for the densityindependence of each is likely the same.

Our results indicate that the amount of vapour emerging from a halothane Cyprane Mark 2 or Ohio enflurane vaporizer is affected by the density of carrier gases. Factory calibration of the dial settings of these vaporizers employs 100 per cent oxygen as the carrier gas (density 1.43 $\mathrm{g} \cdot$ litre $^{-1}$ ); gases of different density will give a vapour concentration somewhat different than that indicated by the dial. This effect will be important when nitrous oxide is included in the carrier gas and/or when density is increased by hyperbaric pressures.

Predicted magnitudes of nitrous oxide effect on the output of both density-dependent vaporizers are given in Table 1 . In the clinical setting, addition of nitrous oxide to the halothane Cyprane Mark 2 at a fixed dial setting increases overall anaesthetic potency in three ways; first, by the added anaesthetic effect of nitrous oxide per se; secondly, by augmenting the fresh gas concentration of halothane through the vaporizer-gas density effect; and thirdly, by further increasing the alveolar level of halothane through the second gas effect. When nitrous oxide is added to the carrier gas of the Ohio enflurane vaporizer, the increased anaesthetic potency resulting from the first and third of these effects would be partially offset by reduced enflurane concentrations emerging from the vaporizer.

Increased ambient pressure increases gas density and in that way might be expected to alter the function of density dependent vaporizers. McDowall reported that two atmospheres of ambient pressure increased the output of the halothane Cyprane Mark 2.7 Our predictions of the effects of hyperbaric pressure are presented in Table II and those for the Mark 2 concur with McDowall's observations.'

\section{ACKNOWLEDGEMENTS}

The authors wish to acknowledge the assistance of E. Caslick and L. Nolan in preparation of this manuscript.

\section{ADDENDUM}

Since the preparation of this manuscript, Nawaf and Stoelting have reported in a Letter to the Editor of Anesthesia and Analgesia (58: 441 (1979)) that their original estimates of the effect of nitrous oxide on the output of the Ohio enflurane vaporizer were in error. Repeating their measurements, they found that nitrous oxide reduced (rather than increased) the ouput of this vaporizer at all settings up to three per cent by magnitudes very similar to those reported here.

\section{REFERENCES}

1. Stoelting, R.K. The effect of nitrous oxide on halothane output from fluotec Mark 2 vaporizers. Anesthesiology 35: 215 (1971).

2. NAwAF, K., \& Stoelting. R.K. Nitrous oxide increases enflurane concentrations delivered by Ethrane vaporizers. Anesth. Analg. 58: 30 (1979).

3. Clark, J.B. Physical and Mathematical Tables. Edinburgh. Oliver and Boyd (1968).

4. Paterson, G.M.. Hulands, G.H. \& Nunn, J.F. Evaluation of a new halathane vaporizer: the Cyprane Fluotec Mark 3. British Journal of Anaesthesia 4I: 109 (1969).

5. HILL, D.W. The design and calibration of vaporizers for volatile anaesthetic agents, pp. 386. In: C. Scurr \& S. Feldman, Scientific Foundations of Anaesthesia, 1st Ed., London (1970).

6. Ohio Ethrane Technical Manual.

7. MCDowalL, D.G. Anaesthesia in a pressure chamber. Anaesthesia 19(3): 321 (1964). 
RÉSUMÉ

Quatre vaporisateurs d'usage courant ont été étudiés en rapport avec les effets de la densité du gaz vecteur sur l'efficacité de la vaporisation. La concentration de vapeur obtenue d'un vaporisateur Cyprane (Fluotec) Mark 2 a augmenté proportionnellement à la densité du gaz vecteur alors que la concentration des vapeur fournie par le vaporisateur Ohio pour l'enflurane a diminué. Les vaporisateurs Cyprane (Fluotec) Mark 3 et Cyprane pour enflurane sont indépendants de la densité du gaz vecteur. Il est d'importance clinique de noter que le mélange protoxyde d'azote-oxygène $(75: 25)$ comparé a l'oxygène seul a fait augmenter la concentration des vapeurs d' halothane à la sortie du vaporisateur Mark 2 à des valeurs allant jusqu’à 30 pour cent et diminuer les concentrations d'enflurane à des valeurs allant jusqu'à 20 pour cent à la sortie du vaporisateur Ohio. 